\title{
Breast Reconstruction
}

\author{
Kendall R. Roehl ${ }^{*}$
}

Department of Surgery, The University of Texas Medical Branch, Galveston, Texas, USA

\begin{abstract}
Breast cancer is one of the most common diseases treated by general and plastic surgeons. Reconstruction of the breast began in the 1960s with the invention of the silicone breast implant. Since then, breast reconstruction has undergone an evolution. It is possible to add a woman's own tissue to enhance an implant reconstruction, as in the latissimus dorsi myocutaneous flap, but often autologous tissue alone is sufficient to create a breast. Initially this was performed using abdominal tissue based on one of the rectus abdominis muscles and the superior epigastric system known as the TRAM (transverse rectus abdominis myocutaneous) flap. Now the same tissue is often transplanted as a free tissue transfer based on the deep inferior epigastric vessels. Strides have been made to lessen the morbidity on the abdominal wall with muscle-preserving operations to include the muscle-sparing TRAM, deep inferior epigastric perforator (DIEP) flap, and superficial inferior epigastric artery (SIEA) flaps. Similarly, in certain situations, gluteal tissue and inner thigh skin and fat can be used to reconstruct a breast, superior and inferior gluteal artery (SGAP/IGAP) flap and transverse upper gracilis (TUG) flaps respectively. The complications of each of these forms of breast reconstruction are reviewed as well. Breast reconstruction often now includes surgery to the noncancerous breast as well, as prophylactic mastectomy is becoming a more popular choice for women. In addition, the effects of radiation in breast conservation therapy are becoming evident and strides are being made to improve cosmetic outcome through breast rearrangement and reduction strategies. Through an alliance among the general and reconstructive surgeons, women's breast cancer needs can be addressed in an individualized manner.
\end{abstract}

Keywords: Autologous reconstruction, TRAM, SIEA, DIEP, SGAP/IGAP, TUG, oncoplastic surgery.

\section{HISTORY}

Breast cancer treatment as we know it began in the late 1800 s with William Halsted who performed the first mastectomy. The Halsted method, and the thought that reconstruction of any kind could compromise tumor ablation, remained the treatment of choice for breast cancer until the 1960s. With the advent of the silicone breast prosthesis for augmentation in 1963, by Cronin and Gerow [1], reconstruction after mastectomy followed suit. This provided a reconstruction with reasonable simulation of shape and texture without the need for multiple, lengthy operations or delay in adjuvant therapies. Delayed insertion of breast prostheses after mastectomy became the mainstay of treatment. In 1971, Snyderman and Guthrie [2] reported a case of immediate reconstruction with subcutaneous placement of implants, and this approach prevailed for the remainder of the decade. Tissue expansion was first used in 1972 by Radovan [3] and allowed for patients with more severe skin deficiencies to ultimately receive implants and have the benefits of reconstruction after mastectomy.

The development of musculocutaneous flaps and microvascular tissue transfers developed after cutaneous vascular territory studies in the $70 \mathrm{~s}$ and $80 \mathrm{~s}$. This has allowed plastic surgeons to replace like tissues with like and is the foundation for breast reconstruction as we know it

*Address correspondence to this author at the Department of Surgery, Division of Plastic Surgery, The University of Texas Medical Branch, 301 University Blvd., Galveston, TX 77555-0724, USA; Tel: (409) 772-1255; Fax: (409) 772-1872; E-mail: krroehl@utmb.edu today. The latissimus dorsi muscle was first used for breast reconstruction in 1977 by Schneider et al. [4], Muhlbauer and Olbrisch [5], and was later popularized by Bostwick et al. [6]. Use of abdominal tissue for breast reconstruction then ensued and was developed by Hartrampf, Scheflan and Black [7]. They described using the vertical rectus muscle and a transverse paddle of overlying skin. Further refinements and modifications of abdominal-based techniques have focused on obtaining a more reliable outcome because of the tenuous blood supply with the pedicled flap. These modifications include delay procedures, bipedicled flaps, free and perforator flaps.

The initial goals in breast reconstruction were to create a reasonable appearance in clothing. Early reconstructions used less than aesthetic skin and the devoid axilla after axillary dissection was not addressed. However, the aesthetic standards today are ever-increasing, and the goal today is to create a breast(s) that is symmetric with natural shape, contour, position, and feel. This has been made possible with the advent of the skin sparing mastectomy, allowing for better skin quality and preservation of the breast footplate.

\section{TIMING}

Because most local tumor recurrences are within the skin and/or subcutaneous adipose tissue or in the axilla, there are few reasons to delay reconstruction. Therefore, immediate reconstruction has become commonplace in America. It affords the psychological benefits to women and is the opportune time to preserve the normal footplate of the breast, most importantly the inframammary fold. This can be much more difficult in a delayed reconstruction setting. Skin flaps are also more pliable in the immediate setting. Currently, 
most women with stage I and II cancer are candidates for immediate reconstruction. Caveats to this do exist in the face of certain chemotherapeutic agents and the need for adjuvant radiotherapy in which immediate reconstruction is not possible. These can interfere with postoperative healing and the aesthetic outcome, respectively.

One must consider, however, the possibility of complications with immediate reconstruction as well. In cases where reconstructions have complications such as delayed wound healing, infection, mastectomy flap loss, and flap necrosis, the initiation of chemotherapy and radiation therapy may require delay and thus compromise in cancer treatment. All of these must be considered by the ablative and reconstructive surgeons as well as the patient in order to determine appropriate timing of reconstruction.

\section{PATIENT SELECTION}

Women have multiple reasons for choosing to undergo breast reconstruction. These include no need for an external prosthesis, fewer limitations with regards to clothing, to regain femininity, and to feel whole again. Others chose not to undergo reconstruction because they feel too old for the procedure or have a fear of complications [8]. Given the myriad of options in breast reconstruction, the operation should be tailored to the patients' wishes as well as their underlying health. There are a small number of relative contraindications to breast reconstruction. Extreme age, severe cardiovascular disease or other comorbidities, extreme obesity and advanced breast disease are possible reasons why breast reconstruction may not be reasonable.

Often women are faced with the choice, in early disease, of breast conservation therapy (BCT) versus mastectomy. Studies show equivalent survival outcomes when comparing the modalities of BCT with radiation and mastectomy. These decisions are often made in conjunction with the ablative surgeon. Patient satisfaction with these two modalities is varied. Pusic and coworkers surveyed women who underwent lumpectomy/XRT, mastectomy and mastectomy with reconstruction. Similar to Reaby's report [8], women who chose reconstruction were younger, Caucasian, and more educated. Interestingly, comfort with nudity was much lower in the mastectomy alone group and quality of life varied with age. Younger women $(<55)$ were least happy with mastectomy alone, whereas the older than 55 group was least satisfied with lumpectomy [9]. Ultimately, the choice is that of the breast cancer patient and must be individualized.

After the advent of BCT, many women chose this option in order to preserve as much of their native breast as possible. The current paradigm has shifted, and more women are choosing to undergo mastectomy. This shift is multifactorial and includes dissatisfaction with the cosmesis of BCT/XRT breasts, skin preservation mastectomies (nipple-sparing and areolar-sparing), improved reconstructive options (silicone gel prostheses and perforator flap reconstructions), genetic testing for BRCA-1 and -2 genes necessitating bilateral mastectomies, increase in contralateral prophylactic mastectomy and bilateral reconstruction in younger women just to name a few. In addition, women who are often diagnosed at younger ages now with higher lifetime risks may have more aggressive disease or multifocal tumors.
Similarly, breast conservation therapy is also evolving. It is now possible to minimize the effects of radiation on the breast after lumpectomy via oncoplastic techniques. These include breast reduction strategies to obliterate the dead space of lumpectomy/segmental mastectomy, and to counteract the contractile forces seen after radiation therapy. These techniques are employed by either a breast surgeon or plastic surgeon. All of these techniques will be further discussed [10, 11].

\section{PROCEDURE SELECTION/SURGICAL PLANNING}

The options for surgical breast reconstruction are varied and include partial and total. Total breast reconstruction involves two common modalities: the use of an expander/implant, autologous tissue, and some combination of the two. Any of these procedures must not delay adjuvant cancer therapies. The most common procedures performed are:

1. tissue expander placement with later exchange for an implant

2. immediate permanent implant placement

3. latissimus dorsi with implant

4. autologous tissue (pedicled)

5. autologous tissue (free)

The choice among these therapies must take into account the need for skin resection, adjuvant radiation therapy, and patient size/aesthetic desires and activity level. Consideration of the opposite breast as well as available donor tissues must be made. Ideally, reconstructive surgeons would just be filling the empty space left after removal of the gland with preservation of the normal footplate of the breast. This is not always the case. In most instances, except for advanced and inflammatory disease, some version of skinsparing mastectomy can be performed. Breast surgeons are also offering nipple- and areolar-sparing mastectomies. These mastectomies allow for more aesthetically pleasing reconstructions as they confine the scar to the area around the skin paddle of a flap, if used. There is no increased cancer risk/recurrence with skin-sparing mastectomy as long as the skin flaps are not too thick. Conversely, the thickness of the skin determines flap survival, and very thin flaps often become necrotic. In large-breasted women, the skin incisions for mastectomy may be modified allowing easy access for the general surgeon and the ability to have scar symmetry for the reconstructive surgeon. Breast reduction patterns can be used for the mastectomy as well as the contralateral symmetry procedure.

Breast reconstruction is much more than just providing a mound on the chest wall. Of utmost importance is the ability to create symmetry. Very nice reconstructions can be a great disappointment if they do not match the contralateral native breast. For the most part, autologous reconstruction provides better symmetry. This is less of an issue in the case of bilateral reconstruction. In planning reconstructions, one must consider not only the size/shape of the opposite breast, but also the position on the chest wall, the location of the inframammary fold, the height/size/color of the nippleareolar complex, and the amount of breast ptosis. 


\section{IMPLANT-BASED RECONSTRUCTIONS}

Implant reconstructions are performed in those women that have a reasonable amount of good quality skin after mastectomy, sufficient enough to completely cover an implant and provide a natural shape. They are advantageous in that they are relatively quick procedures with minimal morbidity to the patient. Implant reconstruction is best used in bilateral reconstructions as it is the best opportunity for symmetry. It is very difficult with implant-only reconstructions to mimic the natural ptosis and contour of the contralateral breast, except in the cases of young women with relatively small, youthful-appearing breasts.

Initially, these reconstructive procedures were performed with placement of the implant in the subcutaneous pocket. This fell out of favor because of visible rippling of the implant beneath a thin layer of skin and a greater complication risk of capsular contracture. Now, these implants are placed in a submuscular pocket beneath the pectoralis major. Some surgeons provide for full-muscle coverage with the assistance of the serratus anterior and the rectus abdominis fascia inferiorly. Others provide coverage of the inferior pole of the implant with bioprosthetic (human, porcine, or bovine dermal allografts) material to help create a natural inframammary fold and contoured reconstruction as well as provide an additional layer between the implant and the inferior mastectomy skin flap. This material is sutured to the pectoralis major muscle superiorly and then inferiorly to the previously marked or designated inframammary fold [1214] (Figs. 1, 2). Either method helps fix the pectoralis major and keeps it from migrating superiorly exposing more of the implant.
A

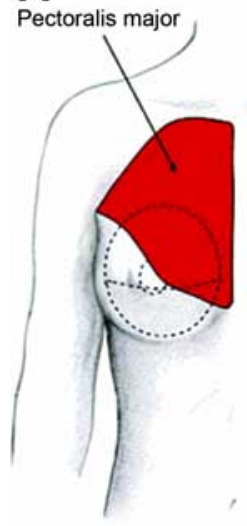

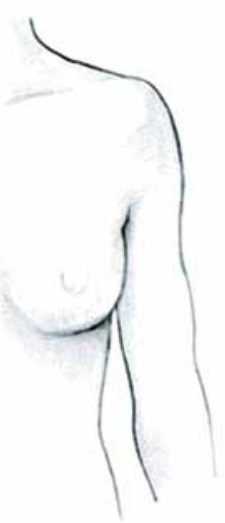

B

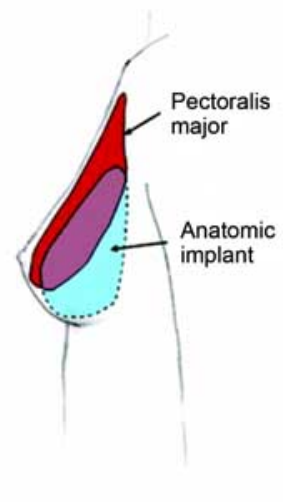

Fig. (1). Schematic representation of implant position, pectoralis position and chest wall. The pectoralis muscle cannot cover the inferior pole of the breast and thus the need for bioprosthetic material in the area of greatest expansion needs. Reprinted with permission from Breuing KH, Warren SM. Ann Plast Surg, 2005; 55:232; Lippincott, Williams \& Wilkins.

Often these forms of reconstruction are begun with placement of a tissue expander at the time of mastectomy. This is to allow for little stress on the tenuous mastectomy flaps initially or to allow for progressive stretching of the skin in order to place a larger implant than would have been safe at the time of mastectomy. Expanders are silicone shell prostheses that have either an integrated or remote port for injection of saline in the clinic setting. Most surgeons expand the skin to a slightly larger size to provide for a large pocket with some ptosis. A period of 4-8 weeks is given prior to exchange of the expanders for implants, allowing for maturation of the capsule and to limit the rapid shrinkage of expanded skin.
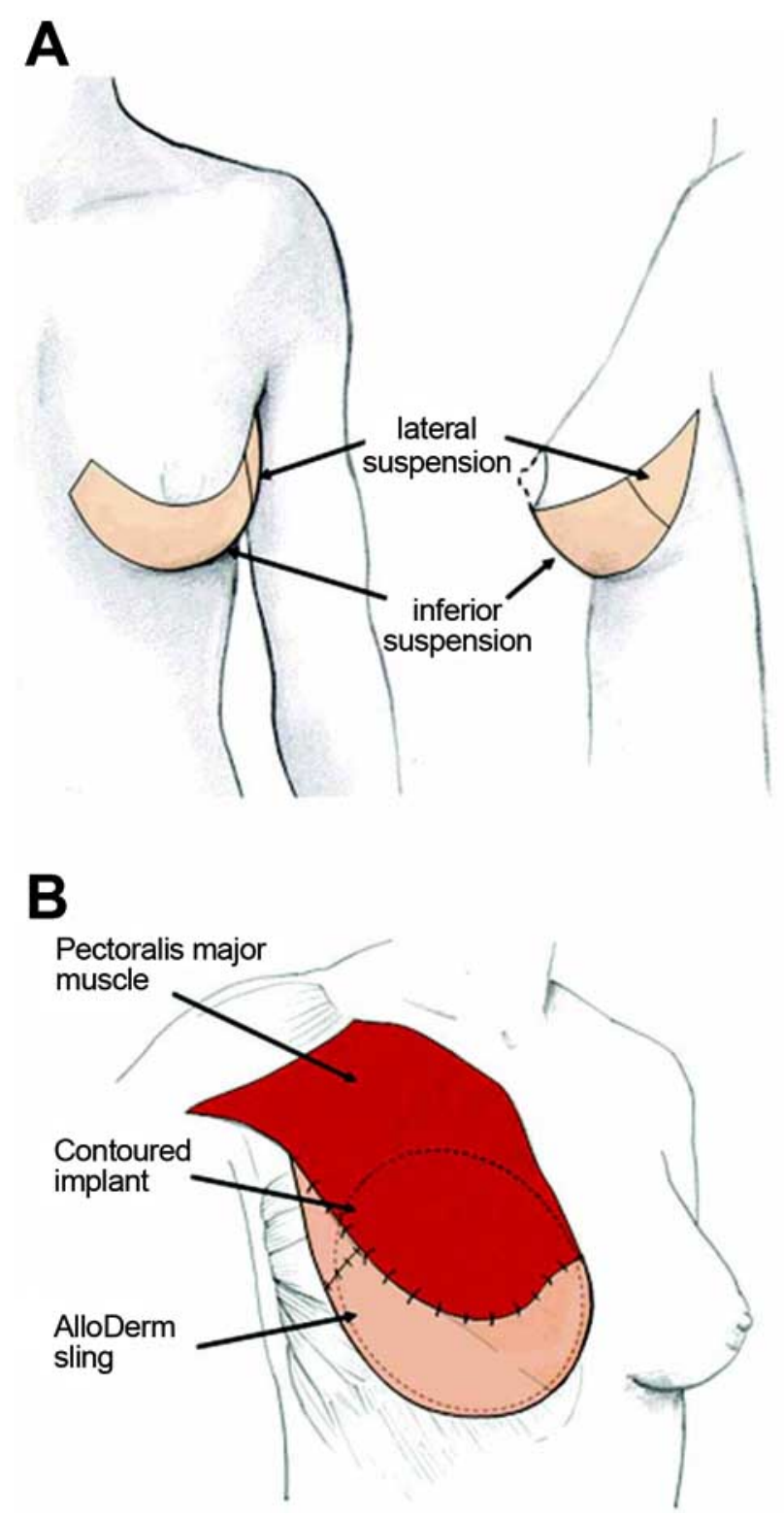

Fig. (2). Schematic representation of chest wall, breast, pectoralis muscle, bioprosthetic sling and implant. Bioprosthetic material is sutured to the inferior border of the pectoralis muscle superiorly, the inframammary fold inferiorly, and curved laterally along the chest wall to recreate the footprint of the breast for expansion. Reprinted with permission from Breuing KH, Warren SM. Ann Plast Surg, 2005; 55:232; Lippincott, Williams \& Wilkins.

In general, implant-based reconstructions provide for a round-shaped youthful breast mound without ptosis (Fig. 3). Some would refer to this as less natural. It requires multiple clinic visits to provide for expansion and then a subsequent procedure to place the permanent implants. This requires a 
time commitment from the patient. Over time, implant reconstructions tend to change due to the effects of gravity, the body's response to foreign objects (capsule formation), and aging of the implants themselves. This occurs linearly with time such that $86 \%$ of women are pleased with their results at 2 years $v s 54 \%$ at 5 years [15].

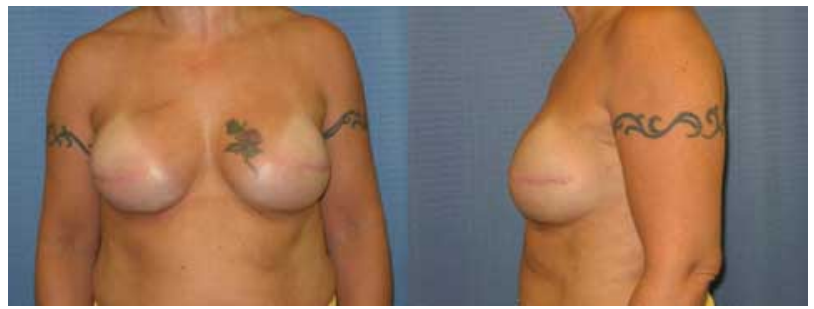

Fig. (3). 41 year-old female with left breast cancer underwent bilateral mastectomy with immediate placement of bilateral tissue expanders with bioprosthetic slings. Final reconstruction with exchange of expanders for $533 \mathrm{cc}$ silicone gel breast prostheses.

\section{COMBINATION RECONSTRUCTION}

Use of autologous tissue in conjunction with an implant was first performed in the 1970s. There is often a need for additional tissue after mastectomy to create a sizable breast and to create a natural breast drape, otherwise known as ptosis. This form of reconstruction most commonly uses myocutaneous latissimus dorsi muscle based on the thoracodorsal artery pedicle as described by Schneider, Hill and Brown [4]. It is a broad, flat muscle that spans the back from the tip of the scapula superiorly, to the spine medially and the iliac crest inferiorly. Most often, the muscle is taken with an overlying skin paddle to replace the removed nipple/areolar complex or larger deficits in the case of traditional mastectomy as popularized by Bostwick et al. [16]. The skin paddle is centered over the muscle and attempts are made to hide the donor-site scar within the bra line. In smaller-breasted women, entire reconstructions can be made of the latissimus dorsi, its overlying fat, and the subscapular fat pad (known as the extended latissimus flap); otherwise, an implant is added. The latissimus dorsi serves as a sling inferiorly, attached to the superior pectoralis to provide full-muscle coverage of the implant (Fig. 4).

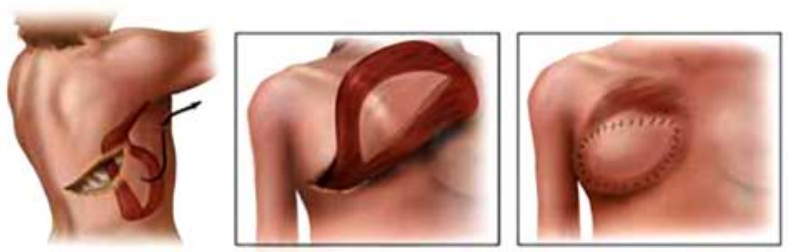

Fig. (4). Schematic representation of latissimus dorsi flap. (left) Flap elevation. (center) Flap transposition. (right) Flap inset. Reprinted with permission from http:/www.mayoclinic.com/health/ medical/IM00280; Latissimus dorsi flap by Mayo Clinic staff; 1998-2009 Mayo Foundation for Medical Education and Research (MFMER).

This flap, performed in a single-stage fashion, is ideal for relatively small-breasted women with some ptosis, but it can be used to create larger reconstructed breasts in a staged fashion. It is also used for reconstruction of lateral partial mastectomy defects. The latissimus flap is advantageous because of its proximity to the breast and reliable circulation. It is the workhorse for reconstruction of unilateral defects in thin women with minimal donor sites, smaller breasted women, and as salvage for any failed breast reconstruction. Its disadvantages, however, are a large scar on the back and the likelihood of donor site complications to be discussed later.

\section{AUTOLOGOUS RECONSTRUCTION (PEDICLED)}

Today, the gold-standard in breast reconstruction with autogenous tissue is the transverse rectus abdominis myocutaneous flap (TRAM) because of the lower abdominal tissue's similarities in consistency with breast tissue. The first description of the RAM flap used in breast reconstruction was with a vertical skin island, Robbins 1979. The TRAM flap as we know it, with a horizontal lower abdominal skin paddle, was first described by Hartrampf thereafter in 1982 [7]. This orients the donor scar into a more acceptable, abdominoplasty location. Although this location of the skin paddle provides for better arc of rotation, the ensuing blood supply to this large volume of tissue is more distal and therefore tenuous. This donor area of skin and adipose tissue has dual blood supply for the superior and inferior epigastric systems. Pedicled flaps are thus supplied by the proximal superior epigastric vessels and the inferior system must be divided from transfer. The small vessels connecting the superior and inferior systems, known as choke vessels, are then dilated to increase perfusion once the deep system is ligated. Studies by Moon and Taylor [17] further elucidated the perfusion zones of the lower abdomen skin territory. They found rich perforating blood vessels that arise out of the rectus to supply the overlying skin and fat. Perfusion is best overlying the rectus muscle (zone I) on the side (pedicle) used, followed by the region overlying the contralateral rectus muscle (zone II), next is the ipsilateral outer region of tissue (zone III), and the region perfused the least is the farthest from the rectus pedicle (zone IV) (Fig. 5).

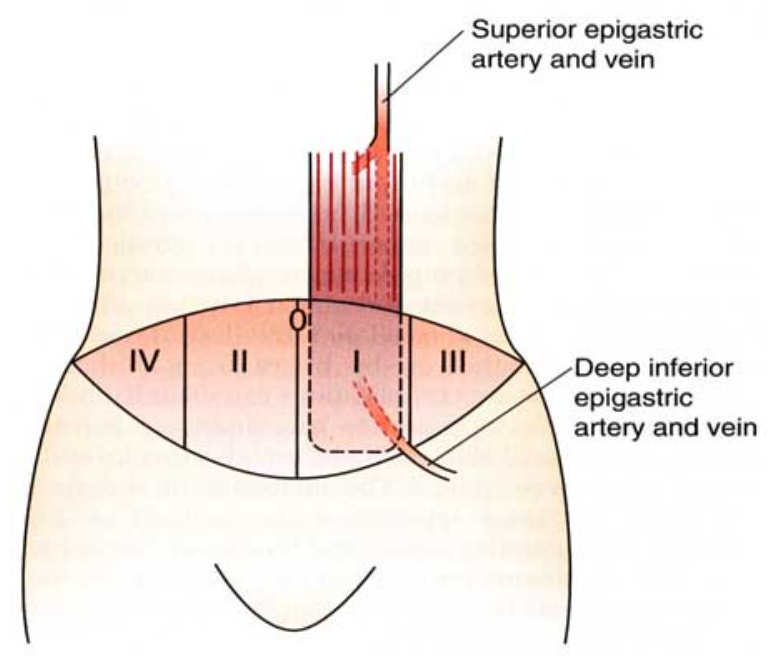

Fig. (5). Vascular territories of the abdominal wall provided by a unilateral TRAM flap as determined by Moon and Taylor [17] Blood flow is best is zone I, followed by II, III, and IV respectively. Reprinted with permission from Wilhelmi BJ, Phillips LG. Breast reconstruction. 2008; 899-914, $18^{\text {th }}$ ed., Sabiston Textbook of Surgery; Elsevier. 
This type of reconstruction is advantageous in that it replaces like with like tissue and provides an acceptable donor scar/improvement of abdominal contour. The limitations include: 1) This tissue has high metabolic demands that are sometimes not met so that portions of the flap go on to form fat necrosis or die; and 2) There is a longer recovery period after this surgery with increased abdominal discomfort and the risk for abdominal weakness and/or hernia formation. Its use can also be limited by previous abdominal operations and scars. Women that are obese, smokers, or have medical comorbidities (especially diabetes) are at greater risk for these complications.

\section{AUTOLOGOUS RECONSTRUCTION (FREE)- ABOMINAL-BASED, GLUTEAL-BASED, AND INNER THIGH-BASED}

\section{Free TRAM Flap, ms TRAM, DIEP, SIEA}

As previously stated, the dominant blood supply to the lower abdomen is the deep inferior epigastric system. Perfusion of the skin and fat based on this system is thus more reliable. It became evident that performing this flap as a free tissue transfer would be beneficial. Free abdominalbased flaps have less partial flap and fat necrosis than pedicled flaps as well as avoid the epigastric bulge of the muscle that occurs in pedicled flaps. In free TRAM flaps, the skin and fat of the lower abdomen is connected via the deep inferior epigastric artery and vein to blood supply either in the axilla (thoracodorsal vessels, originally) or more recently, with the internal mammary artery and vein. This procedure is often done in conjunction with the mastectomy except in advanced disease where adjuvant radiation may be required (Figs. 7-9).

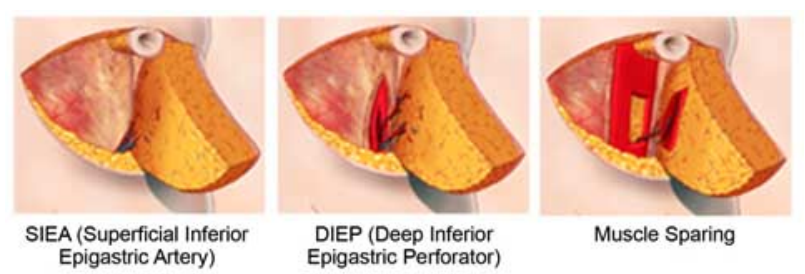

Fig. (6). Schematic representation of the superficial inferior epigastric flap (SIEA) where abdominal wall fascia is undisturbed (left), deep inferior epigastric perforator flap wherein all muscle is spared (center), and the muscle sparing TRAM (msTRAM) in which a small window of muscle is taken around the supplying perforators (right). Reprinted with permission from MD Anderson Cancer Center website: http://www.mdanderson.org/patient-andcancer-information/cancer-information/cancer-topics/cancer-treatm ent/breast-reconstruction/abdominal-flaps.html "Breast reconstruction. Reconstruction using abdominal tissue".

The first to perform this type of reconstruction was Holmstrom in 1979 [18]. Since that time, it and its further refined flaps have become the gold-standard for microvascular autologous breast reconstruction. Original reports from this procedure revealed a partial flap loss rate of $7.1 \%$, total flap loss rate of $1.4 \%$, and fat necrosis in $12 \%$ of smokers but only $3 \%$ in nonsmokers. Abdominal bulge occurred in about $5 \%$ initially but became less as smaller amounts of rectus muscle were harvested, transitioning to the msTRAM [19]. Further refinements of this operation have been made in order to preserve abdominal wall strength.

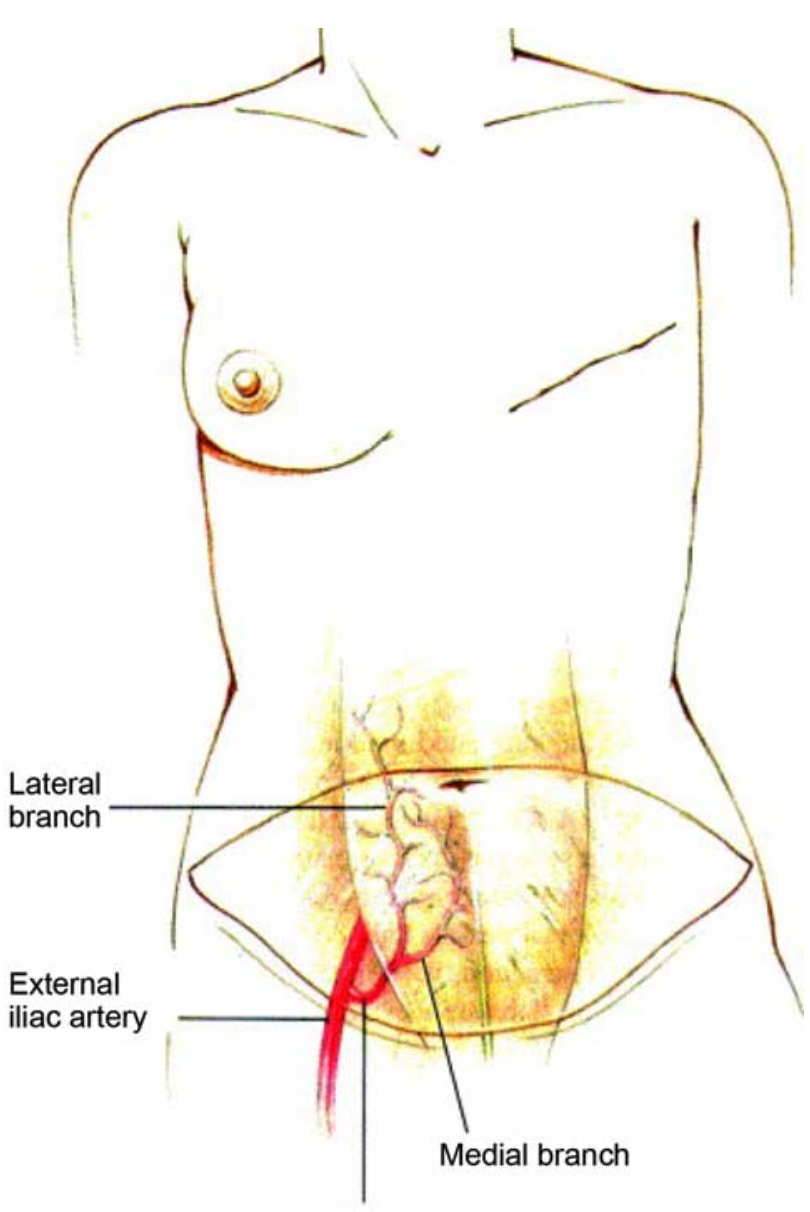

Deep inferior epigastric artery

Fig. (7). Schematic of lower abdomen markings for autologous reconstruction based on the medial and lateral row of perforators based on the deep inferior epigastric artery system. Reprinted with permission from Granzow et al. J Plast Reconstr Aesth Surg, 2006; 59: 571; Elsevier.

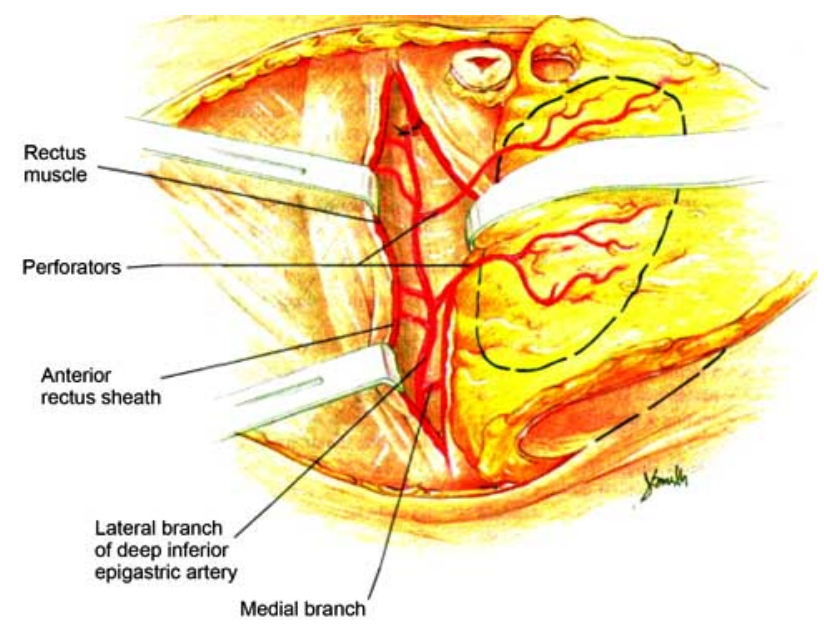

Fig. (8). Anatomy of the deep inferior epigastric artery flap. Perforating vessels, after splitting the rectus abdominis muscle, of the lateral row as they enter the skin and subcutaneous tissue. Reprinted with permission from Granzow et al. J Plast Reconstr Aesth Surg, 2006; 59: 571; Elsevier. 

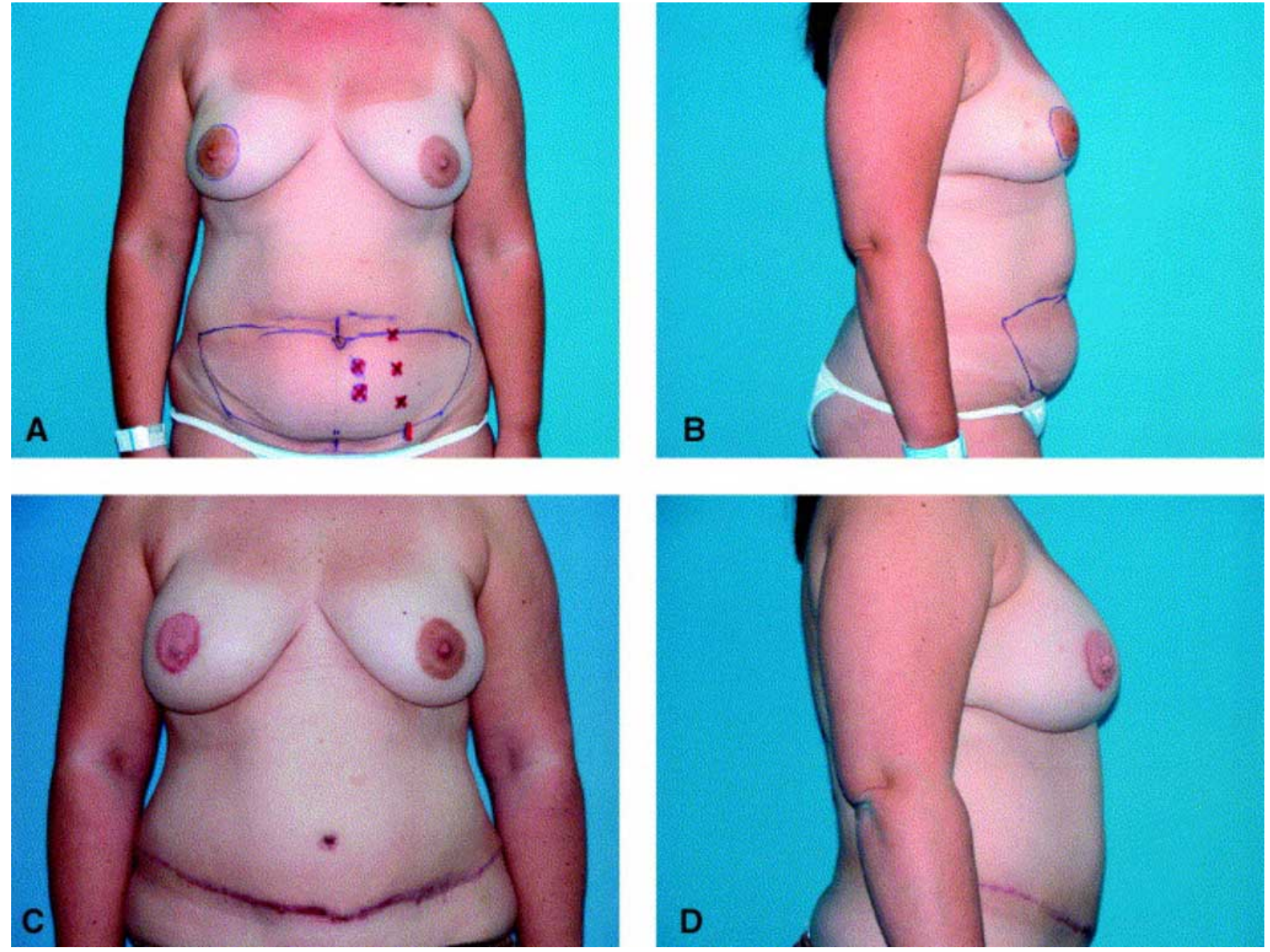

Fig. (9). (A) and (B) Preoperative views of patient with right breast cancer for mastectomy and DIEP reconstruction. (C) and (D) Patient approximately 3 months after breast revision, nipple creation and tattooing. Reprinted with permission from Granzow et al. $J$ Plast Reconstr Aesth Surg, 2006; 59: 571; Elsevier.

The quest to minimize abdominal wall morbidity has led to the development of the muscle-sparing TRAM flap, where only the muscle surrounding the perforating vessels is taken, the DIEP (deep inferior epigastric artery perforator flap) where no muscle is taken and the perforating vessels are dissected out in a chain, and the SIEA (superficial inferior epigastric artery flap) when available (about $30 \%$ ) provides a pedicle that does not penetrate the rectus muscle at all and thus there is no abdominal wall morbidity and shorter recovery time [20,21] (Fig. 6). The choice of flap is often determined by the patient's anatomy. When the SIEA is available and of reasonable caliber, often $>1.5 \mathrm{~mm}$, it is often chosen because it provides the least amount of abdominal morbidity. Difficulties with this flap can occur as the artery is small and there may be some discrepancy between the SIEA and the internal mammary artery. In addition, the SIEA will only support half of the abdominal skin and fat so it is favorable in small breast reconstructions or in bilateral cases. The choice between DIEP and msTRAM is one of the surgeon. When the anatomy is favorable and reasonable caliber perforators are available in a formation that allows for minimal disruption of rectus muscle, a DIEP flap is chosen. When the vessels are smaller or their orientation is not favorable for muscular dissection, an msTRAM is performed. Flap perfusion is often better with an msTRAM, DIEP rates of partial flap loss and fat necrosis are often higher, and thus abdominal wall preservation is sometimes at the expense of flap perfusion and overall breast outcome. Often preoperative imaging studies are used by some to evaluate the vascular system of the anterior abdominal wall. CT angiography, conventional angiography, and even staging CT scans performed during cancer workup have been used to look at the perforators supplying the anterior abdominal skin and subcutaneous tissue. These can provide some guidance as to perforator selection and often decrease dissection times [22].

\section{SGAP/IGAP}

Breast reconstruction can also be performed using tissue from the gluteal region based on either the superior or the inferior gluteal arteries and their overlying skin and subcutaneous tissue. This is commonly performed in women who desire autologous breast reconstruction but have very little adiposity in the lower abdomen. The buttock provides a reasonable amount of fat that is firm and provides nice volume and projection in breast reconstruction. Originally described as a musculocutaneous flap, the GAP flaps had multiple donor site complications including significant seroma, contour deformity and sciatica from nerve compression. They have evolved into a perforator flap design (similar to the evolution of the TRAM flap to the DIEP). Perforator design limits the deformity at the donor 
site and has lessened the incidence of sciatica. The disadvantages of this flap include its difficulty of dissection, short pedicle length and size discrepancy of the gluteal vein when anastomosing it with the internal mammary vein. The flap is technically challenging but provides a good amount of autologous tissue for reconstruction of one or even both breasts [23-26] (Figs. 10-13).

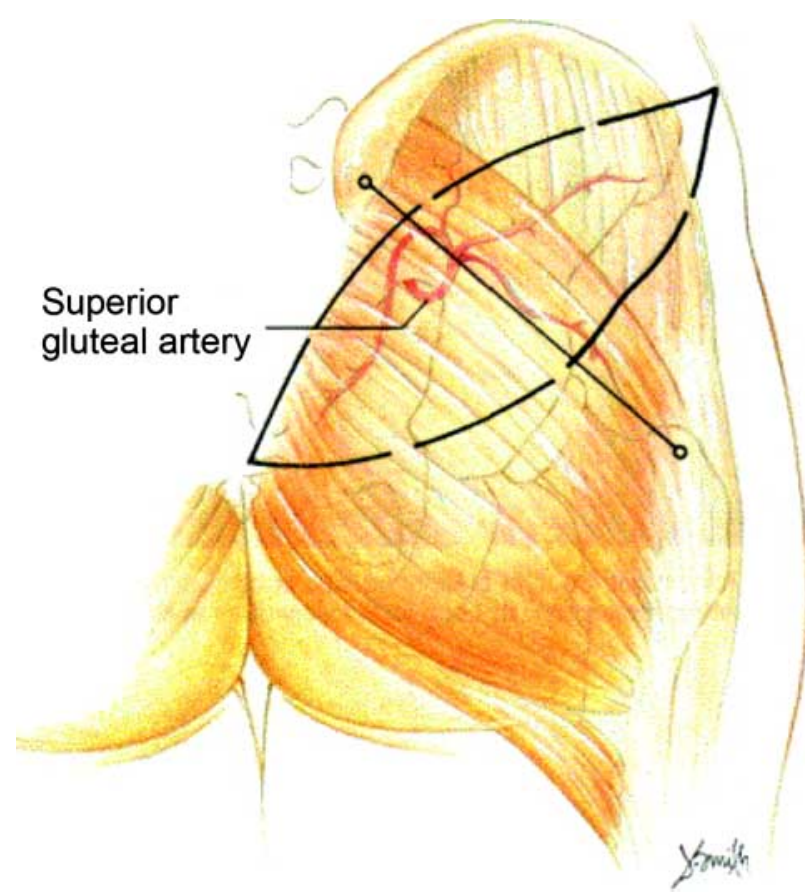

Fig. (10). Skin island location of the SGAP flap. The superior gluteal artery is located one third the distance from the posterior superior iliac spine to the greater trochanter. Reprinted with permission from Granzow et al. J Plast Reconstr Aesth Surg, 2006; 59: 614; Elsevier.

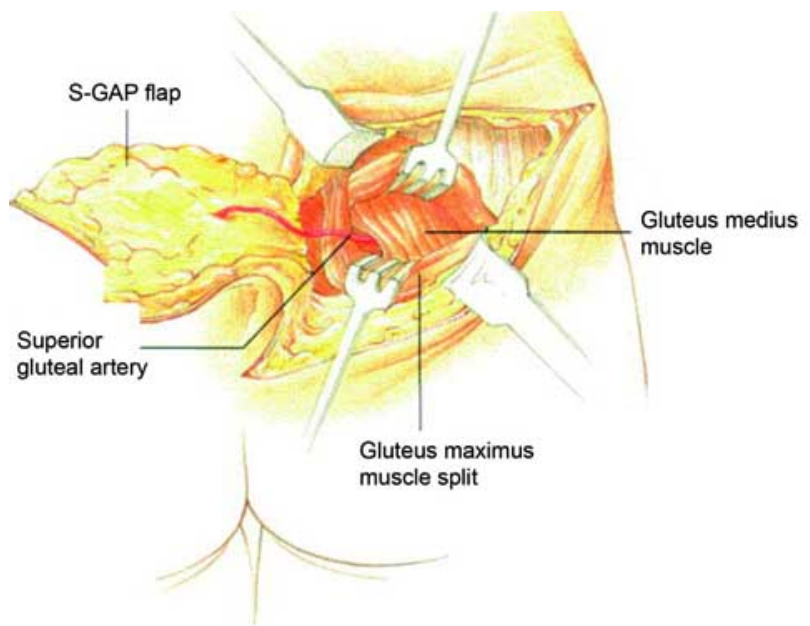

Fig. (11). Superior gluteal vessel dissection through the retracted gluteus maximus muscle. Reprinted with permission from Granzow et al. J Plast Reconstr Aesth Surg, 2006; 59: 614; Elsevier.

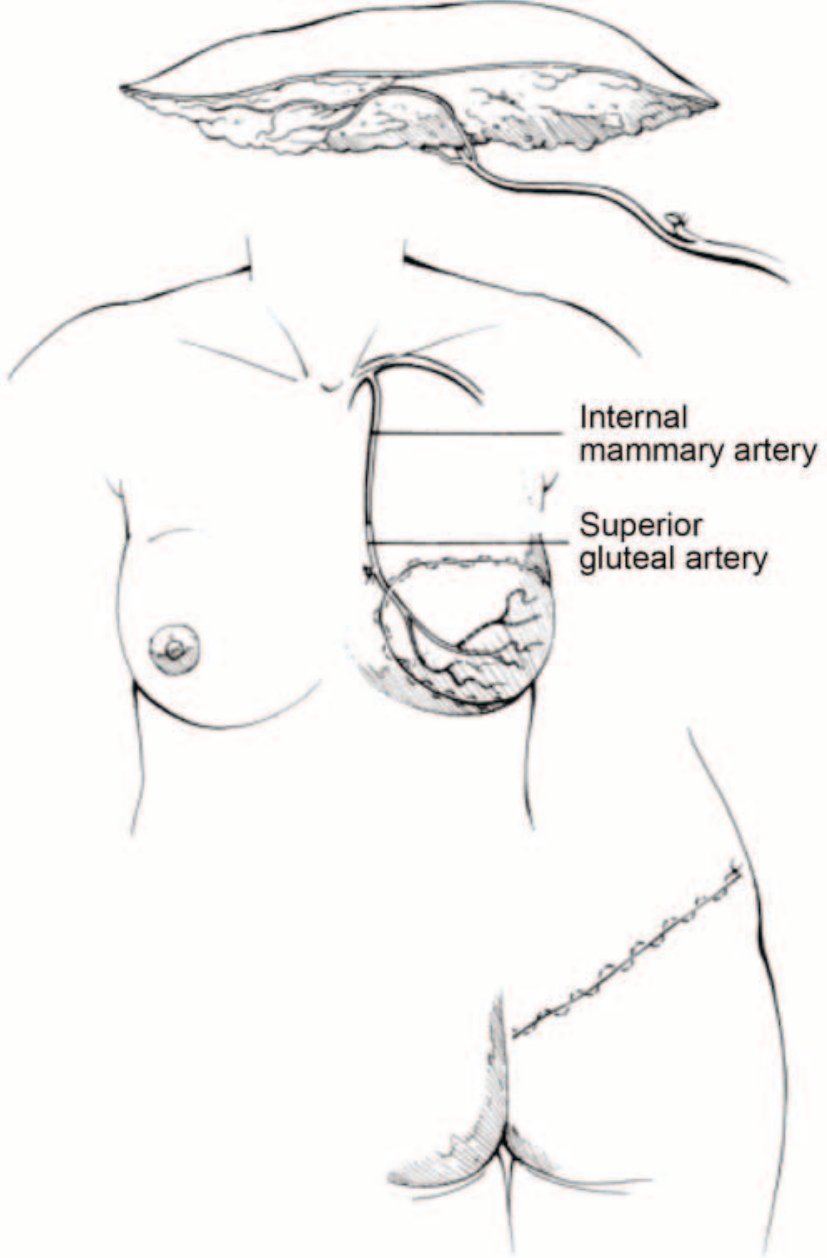

Fig. (12). Schematic of the gluteal perforator flap, inset into the defect via the internal mammary vessels, and donor site closure. Reprinted with permission from Granzow et al. J Plast Reconstr Aesth Surg, 2006; 59: 614; Elsevier.

\section{Transverse Upper Gracilis Flap (TUG)}

Additionally, breast reconstruction can be performed using the upper inner thigh tissue. This is ideal for women without abdominal or gluteal to use as a donor site. Similarly, some women are opposed to the donor scar on the buttock or abdomen and would prefer reduction in the excess fat/skin in the inner thigh region. The TUG flap is based on the ascending branch of the medial circumflex femoral artery and includes the gracilis muscle and the overlying horizontal paddle of skin/fat. The scar is camouflaged in the groin and gluteal fold, and a reasonable amount of tissue can be obtained to reconstruct small to moderate-sized breasts in the immediate setting. Because these flaps are slightly smaller than their abdominal/gluteal counterparts with regards to skin, they are less useful for delayed reconstruction. This flap is rather straight-forward and dissection is somewhat easier than the perforator flaps of the abdomen and buttock. Minimal to no morbidity is noticed with sacrifice of the gracilis muscle. The disadvantages of this flap include a shorter pedicle length, smaller skin island, and the possible 

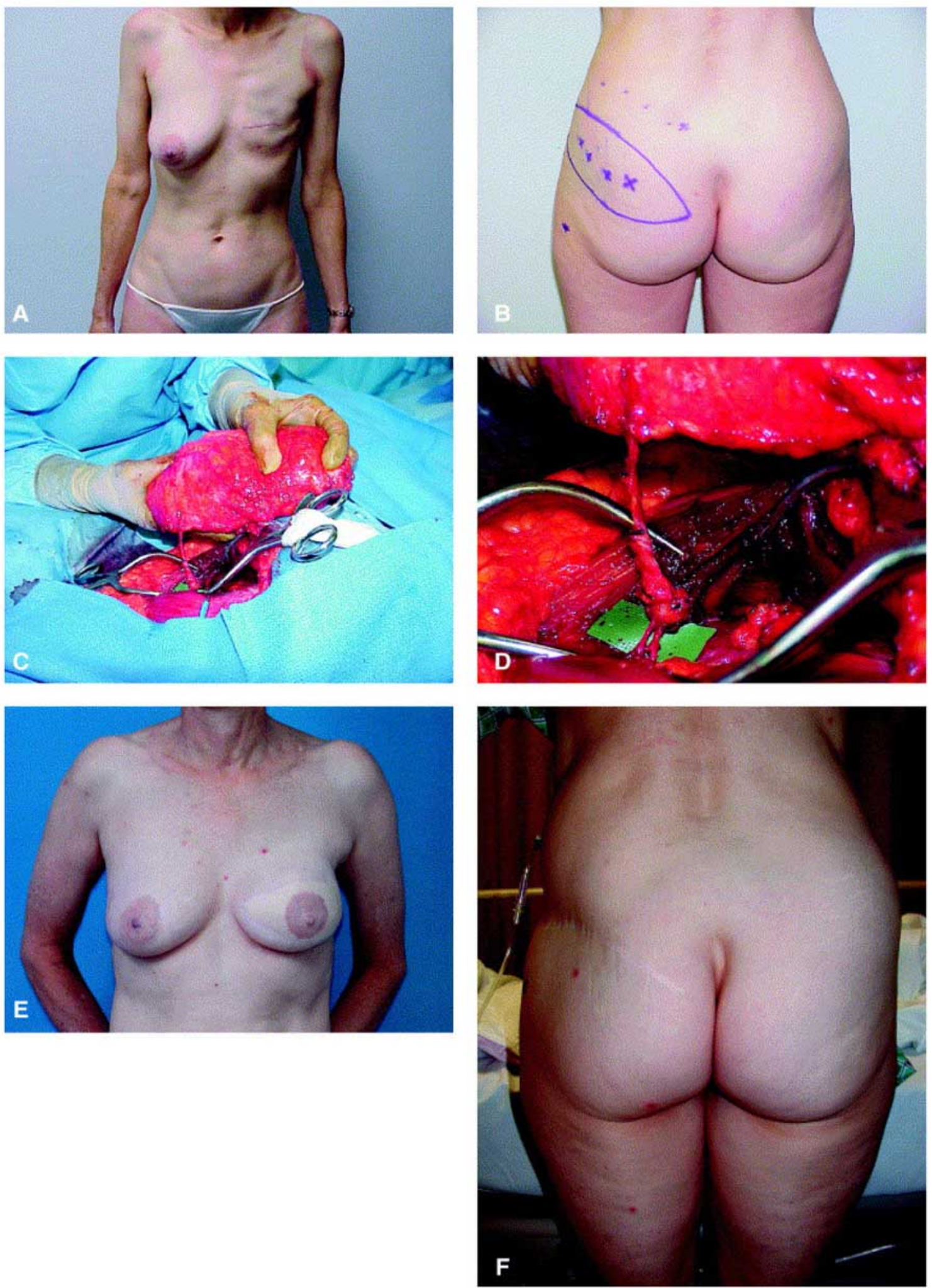

Fig. (13). (A, B) Preoperative view and markings. (C, D) Intraoperative views of flap and superior gluteal artery perforator vessels. (E, F) Postoperative view of patient anterior and posterior 21 months after surgery. Reprinted with permission from Granzow et al. J Plast Reconstr Aesth Surg, 2006; 59: 614; Elsevier.

contour deformity of the medial thigh and widened donor site scar. TUG flaps are ideal for women in whom the abdominal donor site is not available or as a salvage procedure after reconstruction failure [26-29] (Figs. 14, 15).

\section{ONCOPLASTIC SURGERY}

Breast conservation has comparable outcomes in cancer treatment, and up to $40 \%$ of women chose this option in 

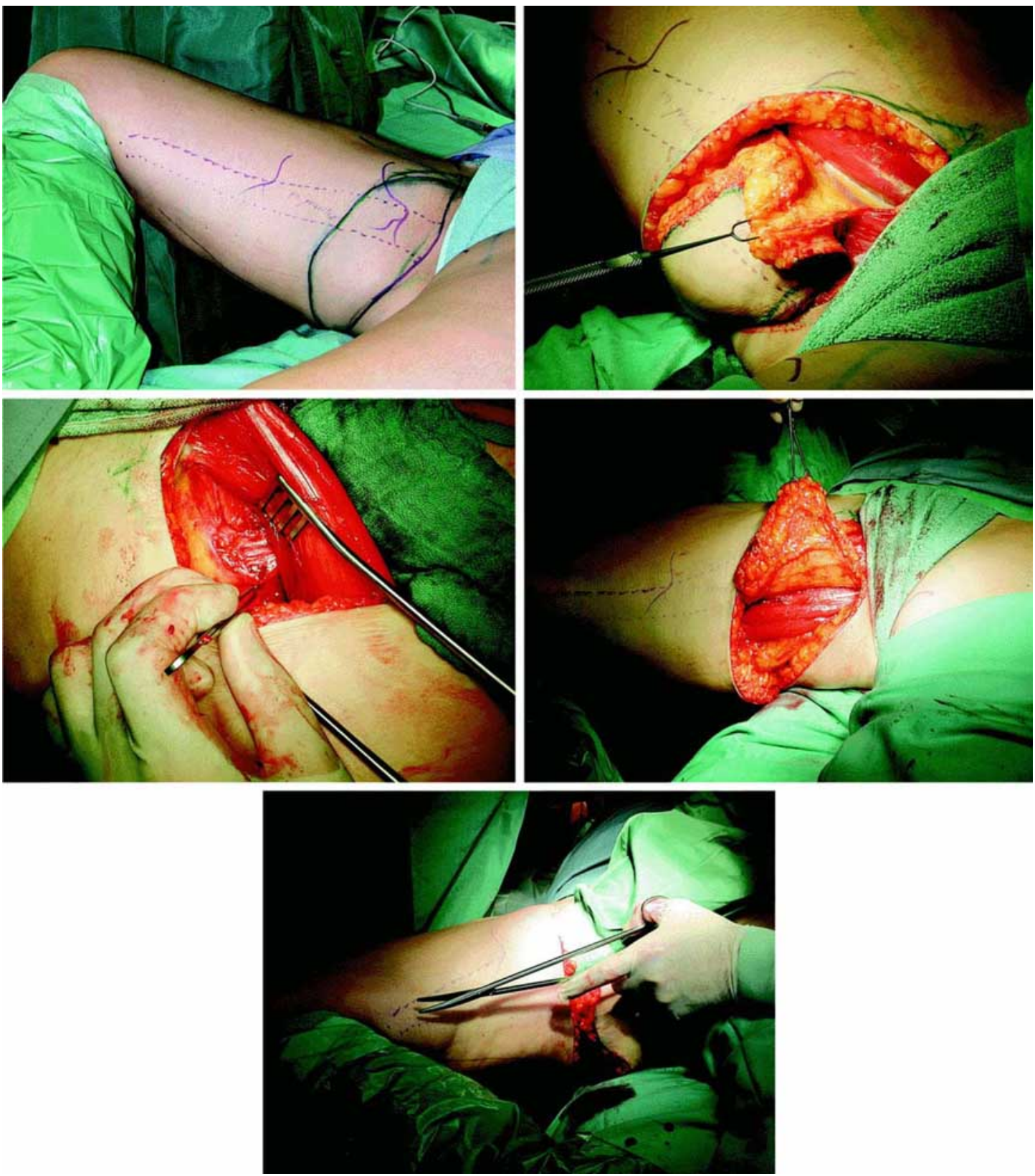

Fig. (14). (Top left) Typical marking of the TUG flap. (Top, right) The anterior portion of the flap is dissected first of the underlying adductor longus. The pedicle, medial circumflex femoral artery, is identified at the dorsal border of this muscle. (Center, left) Posterior portion of the skin island is lifted off the underlying muscle. The overlying skin is supplied by multiple perforators arising from within the gracilis. (Center, right and bottom) After complete skin dissection, the gracilis muscle is cut at its tendinous junction. Reprinted with permission from Schoeller et al. Plast Reconstr Surg, 2008; 122: 29; Lippincott, Williams \& Wilkins.

1991 , increasing to $60 \%$ by 2002 . BCT is a reasonable choice for many because they preserve much of their native breast and often the nipple-areola complex, which is the most disappointing phase of total breast reconstruction. However, the adjunctive radiation that accompanies lumpectomy is not without consequence. At least $30 \%$ of women who chose BCT require some form of reconstructive surgery to achieve better symmetry and $86 \%$ observe asymmetry [30]. Breast revision can be very difficult after radiation therapy with complication rates of $50 \%$ in the radiated breast. Thus, women have been offered reduction of the normal breast for symmetry in clothing and minimal to no surgery on the radiated side in the past. In hopes of improving cosmetic outcomes, we now can provide preemptive treatment at the time of lumpectomy to improve contour and aesthetic deformity after the effects of radiation. This is done in the form of "breast rearrangement" after the cancerous tissue is removed. These types of procedures are ideal in the large-breasted woman, when resection is $20 \%$ of breast volume, tumor location is central/medial/or inferior, when she desires smaller breasts, or when she has significant breast ptosis and/or asymmetry (Fig. 16).

Oncoplastic procedures are either performed immediately or one to two weeks after lumpectomy, once final pathology 

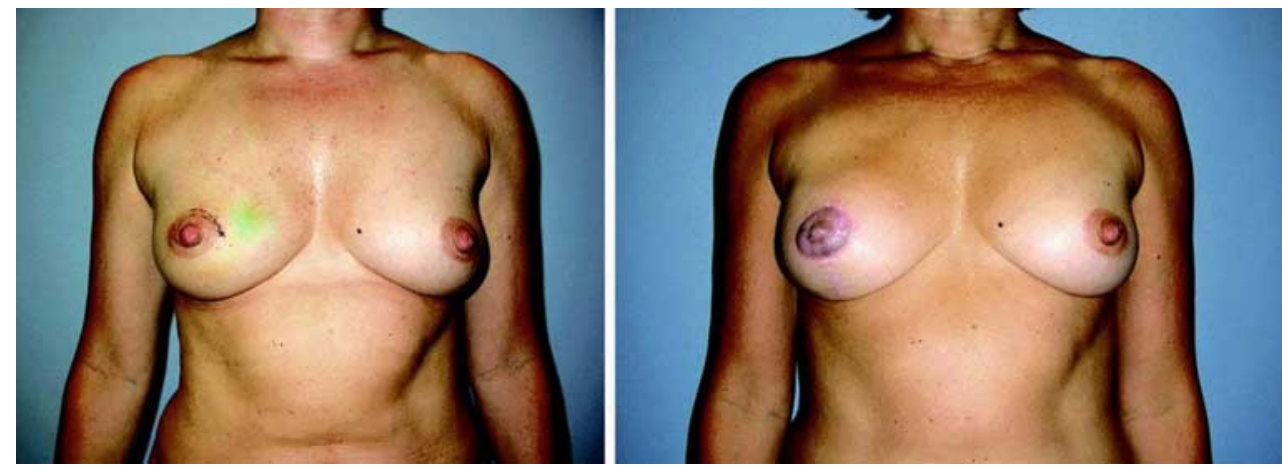

Fig. (15). Patient with right breast cancer before (left) and after (right) unilateral right breast reconstruction using TUG flap. (right) 33 months after reconstruction. Reprinted with permission from Schoeller et al. Plast Reconstr Surg, 2008; 122: 29; Lippincott, Williams \& Wilkins.

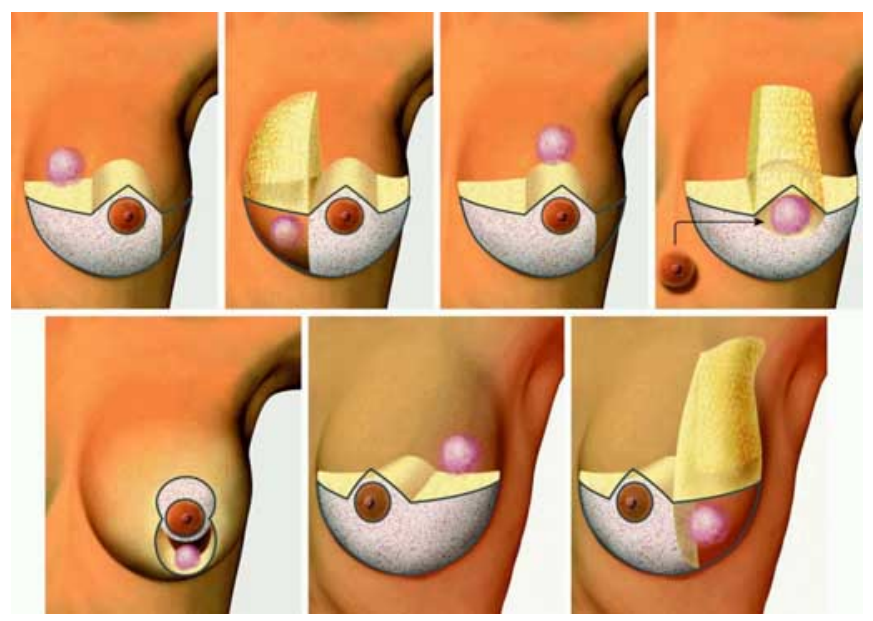

Fig. (16). Guidelines for design of the nipple pedicle to repair a partial mastectomy defect using the breast reduction technique, by tumor location (pink). (Above, left) Upper inner quadrant, showing the inferomedial pedicle (white). The retained medial component (yellow) fills the defect on closure of the Wise skin pattern and maintains the cleavage of the breast. (Above, second from left) Lower inner quadrant, showing the inferolateral pedicle. The retained lateral component provides additional blood supply to the nipple-areola complex. A thick layer of subcutaneous tissue is maintained on the medial aspect of the Wise skin pattern flap to fill the defect on closure of the Wise skin pattern and maintain cleavage of the breast. (Above, second from right) Upper central quadrant, showing the inferomedial pedicle. The retained medial component provides a cosmetic advantage and additional blood supply to the nipple-areola complex in patients with very large ptotic breasts. (Above, right) Middle central quadrant, showing the amputative design with a free nipple graft and maintenance of a thick layer of subcutaneous tissue on the central aspect of the Wise skin pattern flap (yellow). (Below, left) Lower central quadrant, showing the vertical scar reduction mammaplasty. (Below, center) Upper outer quadrant, showing the inferomediolateral pedicle. The retained lateral component fills the defect on closure of the Wise skin pattern. (Below, right) Lower outer quadrant, showing the inferomedial pedicle. The retained medial component provides a cosmetic advantage and additional blood supply to the nipple-areola complex. A thick layer of subcutaneous tissue is maintained on the lateral aspect of the Wise skin pattern flap to fill the defect (yellow). Reprinted with permission from Kronowitz et al. Plast Reconstr Surg, 2008; 122: 1631; Lippincott, Williams \& Wilkins. is available. They include rearrangement of the remaining breast tissue through a variety of techniques, often adhering to breast reduction principles. In addition, more tissue can be brought into the breast to correct the volume deficit, often in the form of latissimus dorsi flap. Indications for these procedures depend on the patient's preoperative breast size, available remaining breast tissue, and overall goals for ultimate breast size and shape. All of these procedures are done prior to radiation to prevent the contracture of the lumpectomy defect and distortion of the nipple areolar complex. Although this technique is rather new, recent outcomes are judged to be quite good. In many instances, these women still require contralateral balancing procedures after the completion of radiation [31-33].

\section{COMPLICATIONS}

Complications can be encountered with any form of breast reconstruction and may cause delay in adjuvant chemotherapy. They include partial or total flap loss, mastectomy flap loss, wound breakdown, and infection. Complications are known to be higher in those women who require adjuvant radiation therapy, and more commonly with implant-based reconstructions (15\% without radiation and up to $42 \%$ with radiation) $[15,34,35]$. Symmetry is also affected by radiation therapy and thus implant-based reconstructions are not the best option in women requiring radiation therapy.

The most common complication with implant-based reconstructions is capsular contracture, which can occur regardless of implant type or placement position. Treatment may require capsulectomy, capsulotomy, change in implant position or type, and implant removal with some other form of reconstruction. Additional complications include infection, seroma, skin slough, necrosis, deflation, and unacceptable appearance.

Satisfaction with this modality of reconstruction tends to decline over time regardless of type, volume, patient age, or type of mastectomy [15]. Thus, implant-based reconstruction is best suited for thin patients with inadequate autologous donor sites or in women who opt not to undergo more lengthy procedures. Implants can also be used to enhance autologous reconstructions to improve symmetry and women's aesthetic wishes. 
Complications associated with flap reconstruction include mastectomy flap issues, partial/total flap loss, and complications related to the flap donor site. For the latissimus dorsi flap, back seroma is the most common complication. In addition, many women require addition of an implant to achieve adequate volume and thus accrue all of the possible implant-related complications. Abdominalbased reconstructions have possible partial flap loss, total flap loss, and fat necrosis which can present later as a firm, suspicious nodule. Fat necrosis occurs in approximately $50 \%$ of pedicled TRAMs $v s 17 \%$ in those performed in a free fashion [20]. Complications associated with the abdominal donor site include flap necrosis, abdominal weakness, bulge, and hernia. Partial flap loss is more common with pedicled reconstructions and total flap loss is more common with free transfer of the abdominal tissue. Partial flap loss rates for free tissue transfers are on the order of $2 \%$ for msTRAM, $7 \%$ for DIEP, $3 \%$ for SIEA, and $4 \%$ for GAP flaps. Fat necrosis also occurs in about $3 \%$ of msTRAMs and $7-9 \%$ for SIEA and DIEPs, respectively. Abdominal weakness and bulge have been reported to occur less in the DIEP setting especially in the face of bilateral breast reconstruction. Multiple studies reveal bulge/hernia formation to occur in about $15 \%$ of pedicled TRAMs versus $<5 \%$ in DIEP flaps [20, 36-38].

Complications of mastectomy flaps and the abdominal wall in autologous reconstructions are much higher in smokers. Smoking is believed to cut down on the microvascular distal circulation of flaps and has little impact on the anastomosis of free flaps. Similar complications are seen in obese and morbidly obese women. They, too, have higher mastectomy flap loss and abdominal donor site complications. Chemotherapy has little effect on the outcomes of breast reconstruction as long as surgical procedures are delayed after neoadjuvant chemotherapy, with return of immunologic function, and little intervention is performed during the course of adjuvant chemotherapy.

Radiation therapy, however, can have some impact on reconstruction. It limits the options for reconstruction in that implant-based procedures have high failure rates. If implants are used, often additional and larger surgeries are required to salvage the breast reconstruction. Similarly, complications associated with irradiated autologous reconstructions are higher. Early complications are similar in delayed and immediate reconstruction with adjuvant radiation therapy. Immediate reconstruction followed by radiation has complication rates of $87 \%$ versus $8.6 \%$ in those that have delayed reconstruction after radiation therapy. In those who have immediate reconstruction, $28 \%$ require additional flap surgery to correct contour deformities [39].

\section{NIPPLE AREOLAR RECONSTRUCTION}

The focus of all of the aforementioned procedures is creation of a breast mound. This provides the woman with symmetry in clothing and a bra. For many women, this is satisfactory and they desire no further operative intervention. For others, they desire completion of their reconstruction to mirror the normal contralateral breast. This requires creation of a nipple and areolar complex. Often these procedures are done some months after the initial mound reconstruction to allow for settling of the reconstruction. This allows for symmetric positioning of the created nipple. In addition, a period of time after radiation should be allotted as the breast reconstruction will undergo some amount of contraction. This is usually 2-3 months after creation of the breast mound or completion of adjuvant therapy.

The nipple itself can be created via a myriad of local flap techniques using the skin of the reconstructed breast mound. Numerous local flap designs have been proposed and all have relatively similar results. Over the first year they undergo some amount of contraction, up to $50 \%$, so all are initially made rather large, accordingly. The areolar reconstruction can be performed in one of two ways. Some surgeons opt to use a full-thickness skin graft, usually from the groin for the native darker pigmentation. Others choose to use medical tattoo pigments that are chosen from a color wheel to match the contralateral native areola. Creation of the areola usually occurs 4-6 weeks after creation of the nipple. Nipple tattoo tends to fade over time and requires occasional touchup.

In general, nipple areolar reconstruction is the least satisfying portion of the overall breast reconstruction experience. The reconstructed nipple and areola has little projection compared to normal, is insensate, and less than the aesthetic normal. This has led surgical oncologists and plastic surgeons alike to attempt to preserve either the areola or the entire nipple areolar complex. This is somewhat controversial because the ducts in the nipple can harbor residual cancer and in addition, blood supply can be tenuous after mastectomy and nipple areolar complex survival is not guaranteed. Nonetheless, cancer is found in very few nipple specimens especially when tumors are small, peripherally located, and with a negative nodal status. This procedure may be applicable to early stage, peripheral breast cancers and even more valuable in prophylactic mastectomies.

\section{MANAGEMENT OF THE CONTRALATERAL BREAST}

The goal in any breast reconstruction is symmetry most importantly in clothing, but plastic surgeons strive for symmetry even out of clothing. In many instances, some revision of the breast mound reconstruction is warranted to improve shape, and operations to the native contralateral breast are necessary as well. Often, mastectomy and reconstruction allows for meeting the patient's desires with regards to breast size, whether smaller or larger. Complete reconstruction of very ptotic or a large breast is often difficult with any of our reconstructive techniques. Thus, techniques employed are augmentation mammaplasty, mastopexy (lifting), and reduction mammaplasty.

The incidence of contralateral cancer is rather low, but is about $1 \%$ per year. So often, young women are opting for prophylactic mastectomy. As well, BRCA-positive women are encouraged to undergo bilateral mastectomies as their incidence of breast cancer is upwards of $80 \%$ in their lifetime. In the case of bilateral mastectomies, reconstruction is best when the same procedure is performed on both sides.

\section{SURVEILLANCE}

Reconstructed breasts are rather easy to monitor for local recurrence as is most often within the skin. Any firm or suspicious mass should be biopsied without delay. The result 
is often fat necrosis in autologous tissue reconstructions. Routine mammography of breast reconstructions is not necessary. Ultrasound and MRI are the most common radiographic tools used. Recurrence is usually managed with surgical excision and adjuvant chemotherapy and/or radiation therapy. Infrequently, does the reconstruction have to be removed in its entirety, only in the case of multifocal recurrence or involvement of the flap pedicle itself.

\section{CONCLUSIONS}

Breast reconstruction is a vital component in the treatment of breast cancer for many women. It is often the optimistic portion of a devastating diagnosis. Reconstruction lessens the psychological and physical burden of the diagnosis for many. When possible, immediate reconstruction is preferred because it has not shown to increase oncologic risk, nor delay adjuvant therapy, provides for better aesthetic outcomes, and provides for less depression. It is also more cost-effective. Planning and decision-making for reconstruction must be individualized to each patient to achieve their desires in the safest, most reasonable fashion. There are pros and cons to each procedure and decision making should be individualized for the patient and her reconstructive surgeon to determine what is the most rational.

\section{REFERENCES}

[1] Cronin TD, Gerow FJ. Augmentation mammaplasty: A new natural feel prosthesis. Transactions of the Third International Congress of Plastic Surgery, Amsterdam: Excerpta Medica 1963.

[2] Snyderman RK, Guthrie RH. Reconstruction of the female breast following radical mastectomy. Plast Reconstr Surg 1971; 47: 5657.

[3] Radovan C. Breast reconstruction after mastectomy using the temporary expander. Plast Reconstr Surg 1982; 69: 195-208.

[4] Schneider WJ, Hill HL, Jr., Brown RG. Latissimus dorsi myocutaneous flap for breast reconstruction. Br J Plast Surg 1977; 30: $277-81$.

[5] Muhlbauer W, Olbrisch R. The latissimus dorsi myocutaneous flap for breast reconstruction. Chir Plast (Berlin) 1977; 4: 27.

[6] Bostwick J, 3rd, Vasconez LO, Jurkiewicz MJ. Breast reconstruction after a radical mastectomy. Plast Reconstr Surg 1978; 61: 682-93.

[7] Hartrampf CR, Scheflan M, Black PW. Breast reconstruction with a transverse abdominal island flap. Plast Reconstr Surg 1982; 69: 216-25.

[8] Reaby LL. Reasons why women who have mastectomy decide to have or not to have breast reconstruction. Plast Reconstr Surg 1998; 101: 1810-8.

[9] Pusic A, Thompson TA, Kerrigan CL, et al. Surgical options for the early-stage breast cancer: factors associated with patient choice and postoperative quality of life. Plast Reconstr Surg 1999; 104: 1325-33.

[10] McGuire KP, Santillan AA, Kaur P, et al. Are mastectomies on the rise? A 13-year trend analysis of the selection of mastectomy versus breast conservation therapy in 5865 patients. Ann Surg Oncol 2009; 16: 2682-90.

[11] Warren AG, Morris DJ, Houlihan MJ, Slavin SA. Breast reconstruction in a changing breast cancer treatment paradigm. Plast Reconstr Surg 2008; 121: 1116-26.

[12] Gamboa-Bobadilla GM. Implant breast reconstruction using acellular dermal matrix. Ann Plast Surg 2006; 56: 22-25.

[13] Breuing KH, Warren SM. Immediate bilateral breast reconstruction with implants and inferolateral AlloDerm slings. Ann Plast Surg 2005; 55: 232-9.

[14] Spear SL, Parikh PM, Reisin E, Menon NG. Acellular dermisassisted breast reconstruction. Aesthetic Plast Surg 2008; 32: 41825.

[15] Clough KB, O'Donoghue JM, Fitoussi AD, Nos C, Falcou MC. Prospective evaluation of late cosmetic results following breast reconstruction: I. Implant reconstruction. Plast Reconstr Surg 2001; 107: 1702-9.

[16] Bostwick J, 3rd, Scheflan M. The latissimus dorsi musculocutaneous flap: a one-stage breast reconstruction. Clin Plast Surg 1980; 7: 71-8

[17] Moon HK, Taylor GI. The vascular anatomy of rectus abdominis musculocutaneous flaps based on the deep superior epigastric system. Plast Reconstr Surg 1988; 82: 815-32.

[18] Holmstrom $\mathrm{H}$. The free abdominoplasty flap and its use in breast reconstruction. An experimental study and clinical case report. Scand J Plast Reconstr Surg 1979; 13: 423-27.

[19] Garvey PB, Buchel EW, Pockaj BA, et al. DIEP and pedicled TRAM flaps: a comparison of outcomes. Plast Reconstr Surg 2006; 117: 1711-21.

[20] Schusterman MA, Kroll SS, Miller MJ, et al. The free transverse rectus abdominis musculocutaneous flap for breast reconstruction: one center's experience with 211 consecutive cases. Ann Plast Surg 1994; 32: 234-42.

[21] Chevray PM. Breast reconstruction with superficial inferior epigastric artery flaps: a prospective comparison with TRAM and DIEP flaps. Plast Reconstr Surg 2004; 114: 1077-85.

[22] Man LX, Selber JC, Serletti JM. Abdominal wall following free TRAM or DIEP flap reconstruction: a meta-analysis and critical review. Plast Reconstr Surg 2009; 124: 752-64.

[23] Guerra AB, Metzinger SE, Bidros RS, Gill PS, Dupin CL, Allen RJ. Breast reconstruction with gluteal artery perforator (GAP) flaps: a critical analysis of 142 cases. Ann Plast Surg 2004; 52: $118-25$.

[24] Allen RJ, Levine JL, Granzow JW. The in-the-crease inferior gluteal artery perforator flap for breast reconstruction. Plast Reconstr Surg 2006; 118: 333-9.

[25] Granzow JW, Levine JL, Chiu ES, Allen RJ. Breast reconstruction with gluteal artery perforator flaps. J Plast Reconstr Aesthet Surg 2006; 59: 614-21.

[26] Guerra AB, Soueid N, Metzinger SE, et al. Simultaneous bilateral breast reconstruction with superior gluteal artery perforator (SGAP) flaps. Ann Plast Surg 2004; 53: 305-10.

[27] Schoeller T, Huemer GM, Wechselberger G. The transverse musculocutaneous gracilis flap for breast reconstruction: guidelines for flap and patient selection. Plast Reconstr Surg 2008; 122: 2938.

[28] Arnez ZM, Pogorelec D, Planinsek F, Ahcan U. Breast reconstruction by the free transverse gracilis (TUG) flap. Br J Plast Surg 2004; 57: 20-6

[29] Fattah A, Figus A, Mathur B, Ramakrishnan VV. The transverse myocutaneous gracilis flap: technical refinements. J Plast Reconstr Aesthet Surg 2010; 63: 305-13.

[30] Bajaj AK, Kon PS, Oberg KC, Miles DA. Aesthetic outcomes in patients undergoing breast conservation therapy for the treatment of localized breast cancer. Plast Reconstr Surg 2004; 114: 1442-9.

[31] Losken A, Hamdi M. Partial breast reconstruction: current perspectives. Plast Reconstr Surg 2009; 124: 722-36.

[32] Kronowitz SJ, Kuerer HM, Buchholz TA, Valero V, Hunt KK. A management algorithm and practical oncoplastic surgical techniques for repairing partial mastectomy defects. Plast Reconstr Surg 2008; 122: 1631-47.

[33] Berry M, Fitoussi AD, Curnier A, Couturaud B, Salmon RJ. Oncoplastic breast surgery: A review and systematic approach. J Plast Reconstr Aesthet Surg 2009; June 24 [epub ahead of print].

[34] Chawla AK, Kachnic LA, Taghian AG, Niemierko A, Zapton DT, Powell SN. Radiotherapy and breast reconstruction: complications and cosmesis with TRAM versus tissue expander/implant. Int J Radiat Oncol Biol Phys 2002; 54: 520-6.

[35] Benediktsson K, Perbeck L. Capsular contracture around salinefilled and textured subcutaneously-placed implants in irradiated and non-irradiated breast cancer patients: five years of monitoring of a prospective trial. J Plast Reconstr Aesthet Surg 2006; 59: 2734.

[36] Blondeel N, Vanderstraeten GG, Monstrey SJ, et al. The donor site morbidity of free DIEP flaps and free TRAM flaps for breast reconstruction. Br J Plast Surg 1997; 50: 322-30.

[37] Nahabedian MY, Dooley W, Singh N, Manson PN. Contour abnormalities of the abdomen after breast reconstruction with abdominal flaps: the role of muscle preservation. Plast Reconstr Surg 2002; 109: 91-101. 
[38] Bottero L, Lefaucheur JP, Fadhul S, Raulo Y, Collins ED, Lantieri L. Electromyographic assessment of rectus abdominis muscle function after deep inferior epigastric perforator flap surgery. Plast Reconstr Surg 2004; 113: 156-61.
[39] Tran NV, Chang DW, Gupta A, Kroll SS, Robb GL. Comparison of immediate and delayed free TRAM flap breast reconstruction in patients receiving postmastectomy radiation therapy. Plast Reconstr Surg 2001; 108: 78-82.

(C) Kendall R. Roehl; Licensee Bentham Open.

This is an open access article licensed under the terms of the Creative Commons Attribution Non-Commercial License (http://creativecommons.org/licenses/by-nc/ $3.0 /$ ) which permits unrestricted, non-commercial use, distribution and reproduction in any medium, provided the work is properly cited 